\title{
Aerobic aromatization of 1,3,5-triarylpyrazolines in open air and without catalyst
}

\author{
Ronnie N. Jenkins, George M. Hinnant, Andrew C. Bean, and Chad E. Stephens* \\ Department of Chemistry and Physics, Augusta University, Augusta, Georgia 30904 \\ E-mail: cstephe7@gru.edu
}

DOI: $\underline{\text { http://dx.doi.org/10.3998/ark.5550190.p009.458 }}$

\begin{abstract}
A convenient method for aerobic aromatization of 1,3,5-triarylpyrazolines to the corresponding pyrazoles by simply heating in dimethyl sulfoxide (DMSO) in an open atmosphere without catalyst is reported.
\end{abstract}

Keywords: Pyrazoline, pyrazole, oxidative aromatization, aerobic reactions, dimethyl sulfoxide

\section{Introduction}

1,3,5-Triarylpyrazoles have attracted considerable interest because of their vast biological activities, including their estrogenic, ${ }^{1}$ analgesic, ${ }^{2}$ antimicrobial, ${ }^{3}$ anti-inflammatory, ${ }^{4}$ hypoglycemic, ${ }^{5}$ anti-hypertensive ${ }^{6}$ and anti-cancer ${ }^{7}$ activity. Such pyrazoles have also recently been used as scaffolds for design of phosphine-based transition metal ligands ${ }^{8}$ and as fluorescent probes for cellular biochemistry. ${ }^{9}$ Given such interest, various methods have been reported for the synthesis of these triarylpyrazoles. One of the most common routes to these compounds involves oxidative aromatization of the corresponding pyrazolines (4,5-dihydropyrazoles), since these are readily obtained by reaction of a chalcone with a hydrazine derivative. ${ }^{10}$ Reagents used for this aromatization are diverse and have included manganese dioxide, ${ }^{5}$ lead tetraacetate, ${ }^{11}$ mercury oxide, ${ }^{12}$ potassium permanganate, ${ }^{13}$ various nitrates, ${ }^{14-16}$ 2,3-dichloro-5,6-dicyano-1,4benzoquinone (DDQ), ${ }^{17}$ hypervalent iodine reagents, ${ }^{18}$ calcium hypochlorite, ${ }^{19} \mathrm{~N}-$ bromosuccinimide, ${ }^{20}$ iodic acid, ${ }^{21}$ trichloroisocyanuric acid, ${ }^{22}$ a 1,3,4-triazole-3,5-dione, ${ }^{23}$ hydrogen peroxide/ $\mathrm{NaI}$ or oxalic acid/NaI, ${ }^{24}$ and a $\mathrm{DABCO}-\mathrm{Br}_{2}$ complex. ${ }^{25}$ As a more unusual reagent, human hemoglobin in the presence of hydrogen peroxide has also been used. ${ }^{26}$ More attractive, however, is the prospect of oxidizing pyrazolines with elemental oxygen rather than traditional chemical reagents. Such aerobic aromatization has the potential benefit of being more chemoselective, more cost effective and more environmentally friendly.

To date, a few different synthetic procedures for aromatization of 1,3,5,-triarylpyrazolines under an atmosphere of pure oxygen have been described. These methods employ either 
hydrogen tetrachloroaurate, ${ }^{27} \mathrm{~N}$-hydroxyphthalimide/Co(OAc) $)_{2},{ }^{28}$ or activated carbon as catalyst, ${ }^{29}$ while another is performed without catalyst. ${ }^{30}$ As an alternative to the use of pure oxygen, a few methods have also been reported that use a more convenient open air method for the aerobic oxidation. One of these methods employs a rather large amount of a $\mathrm{Pd} / \mathrm{C}$ catalyst (20 weight \%), with heating in acetic acid. ${ }^{30}$ While operationally convenient, the cost and disposal of the catalyst, the use of acetic acid (a respiratory hazard), and the potential for side reactions when using $\mathrm{Pd}$, such as dehalogenation, ${ }^{31}$ make this method less than optimal. Another open air method employs $\mathrm{FeCl}_{3}(10 \%)$ as catalyst, but still uses acetic acid as solvent. ${ }^{32}$

As an alternative to acetic acid, dimethyl sulfoxide (DMSO), a less hazardous solvent, has also recently been employed. Thus, $\mathrm{Kadu}^{33}$ has described the open air aromatization of some 1,4-diaroyl substituted pyrazolines by microwave heating in DMSO using iodine as promoter, while Lokhande and co-workers ${ }^{34}$ have described the aromatization of some phenol-substituted triarylpyrazolines to the pyrazoles by conventional heating in DMSO using $\mathrm{CuCl}_{2}$ as catalyst. However, since the pyrazolines employed in these reports were uniquely substituted, especially the $\mathrm{N}$-aroylpyrazolines used by Kadu, and specialized microwave heating is used in the other method, the full scope and utility of these open air methods using DMSO remains to be shown. The microwave method also still employs a rather large amount of the $\mathrm{CuCl}_{2}$ catalyst (20 mole\%). Thus, further development of aerobic aromatization methods using DMSO as solvent is warranted.

About 15 years ago now, Huang and Katzenellenbogen ${ }^{35}$ noted the isolation of a single 1,3,5triarylpyrazole by reaction of a chalcone with phenyl hydrazine in open air using DMSO as solvent. Although this reaction typically yields the pyrazoline when performed in various other solvents, the use of DMSO as solvent led to in situ oxidation/aromatization of the initially formed pyrazoline to the pyrazole. Importantly, there was no catalyst employed in the reaction. These authors, however, did not further develop this chemistry as a well-defined method for aromatization of 1,3,5-triarylpyrazolines. Likely because of this, and the fact that the aromatization occurred in situ, their observation has not been referenced in any of the numerous reports related to the topic since then. Thus, with this little known precedent in mind, we set out to further explore and standardize the aromatization of 1,3,5-triarylpyrazolines by simple heating in DMSO. As a result, we now wish to describe a very practical aromatization procedure that involves simply heating the 1,3,5-triarylpyrazoline in DMSO at about $110{ }^{\circ} \mathrm{C}$ for $24-48$ hours in open air and without catalyst to give the corresponding pyrazole in good to excellent yield following purification.

\section{Results and Discussion}

The method we explored involved heating the pyrazoline in DMSO at $110{ }^{\circ} \mathrm{C}$ in an open atmosphere (Table 1). The reaction progress was monitored by TLC, which showed that aromatization proceeded at a relatively slow rate. Nonetheless, by heating for $\sim 24-48 \mathrm{hr}$, we were able to observe complete conversion for a number of pyrazolines containing substituents on 
the 3- and/or 5-phenyl rings. Crude pyrazoles were isolated by adding water to the reaction mixture to precipitate the solid product. Chromatography was then used to remove a trace of a green or orange polar byproduct, possibly the N-oxide or derivative thereof, ${ }^{30}$ and to give the pure pyrazoles in good yield. Recrystallization from hexanes or EtOH gave analytical samples with sharp melting points, which compared well to literature data when known. Known products were also confirmed by ${ }^{1} \mathrm{H}$ NMR data. Novel products were characterized by ${ }^{1} \mathrm{H}$ and ${ }^{13} \mathrm{C} \mathrm{NMR}$, IR, mass spectrometry and combustion analyses. Reaction times, yields and physical data are given in Table 1. As noted in the Table, the yields for entries 2-4 are each higher compared to the reported yields obtained by heating the pyrazoline in $\mathrm{AcOH}$ without catalyst under an oxygen atmosphere. $^{30}$

Table 1. Aromatization of 1,3,5-triarylpyrazolines to the corresponding pyrazoles using DMSO
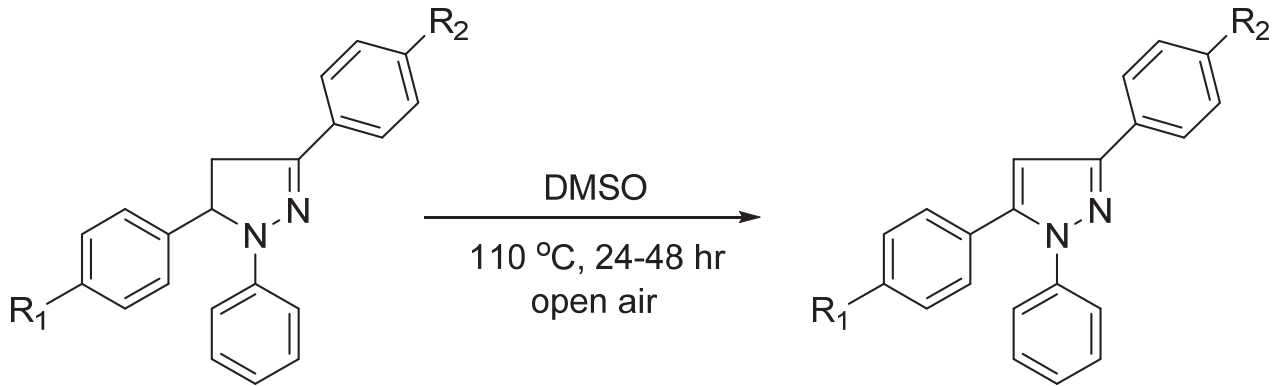

\begin{tabular}{|c|c|c|c|c|c|c|c|}
\hline Entry & $\mathrm{R}_{1}$ & $\mathrm{R}_{2}$ & $\begin{array}{l}\text { Rxn } \\
\text { Time } \\
\text { (hrs) }\end{array}$ & $\begin{array}{c}\text { Isolated } \\
\text { Yield } \\
(\%)\end{array}$ & $\begin{array}{l}\mathrm{Mp}\left({ }^{\circ} \mathrm{C}\right) \\
\text { (Found) }\end{array}$ & $\begin{array}{c}\mathrm{Mp}\left({ }^{\circ} \mathrm{C}\right) \\
\text { (Reported) }\end{array}$ & Product Appearance \\
\hline 1 & $\mathrm{H}$ & $\mathrm{H}$ & 44 & 60 & $135-136$ & $136-137^{8 a}$ & Pale yellow needles \\
\hline 2 & $\mathrm{Cl}$ & $\mathrm{H}$ & 48 & $70(62)^{a}$ & $104-105$ & $104-105^{30}$ & Lustrous white needles \\
\hline 3 & $\mathrm{CH}_{3} \mathrm{O}$ & $\mathrm{H}$ & 48 & $87(54)^{a}$ & $74-76$ & $75-77^{15}$ & Lustrous yellow crystals \\
\hline 4 & $\mathrm{NO}_{2}$ & $\mathrm{H}$ & 25 & $65(45)^{a}$ & $137-138$ & $139-140^{37}$ & $\begin{array}{c}\text { Transparent yellow } \\
\text { crystals }\end{array}$ \\
\hline 5 & $\mathrm{CF}_{3}$ & $\mathrm{H}$ & 46 & 84 & $146-147$ & Novel & Lustrous golden crystals \\
\hline 6 & $\mathrm{CH}_{3}$ & $\mathrm{H}$ & 27 & 76 & $113-114$ & $113-115^{38}$ & $\begin{array}{c}\text { Transparent colorless } \\
\text { crystals }\end{array}$ \\
\hline 7 & $\mathrm{H}$ & $\mathrm{CN}$ & 46 & 85 & $172-173$ & Novel & Pale yellow crystals \\
\hline 8 & $\mathrm{CH}_{3} \mathrm{O}$ & $\mathrm{Cl}$ & 48 & 36 & $110-111$ & $111-112^{39}$ & Lustrous white platelets \\
\hline 9 & $\mathrm{Br}$ & $\mathrm{CH}_{3}$ & 27 & 60 & $105-106$ & Novel & $\begin{array}{l}\text { Pale yellow } \\
\text { microneedles }\end{array}$ \\
\hline 10 & $\mathrm{CH}_{3}$ & $\mathrm{Cl}$ & 48 & 79 & $98-99$ & $\begin{array}{c}\text { Not } \\
\text { given }^{40}\end{array}$ & Lustrous yellow needles \\
\hline
\end{tabular}

${ }^{a}$ Reported yield for aromatization performed by heating in $\mathrm{AcOH}$ under $\mathrm{O}_{2}$ atmosphere. ${ }^{30}$ 
Satisfied with the operational simplicity of the method, we made no attempts to decrease the reaction time by raising the reaction temperature or by blowing air through the reaction, which has been done with other DMSO oxidations. ${ }^{36}$ Regarding the identity of the oxidant for this reaction, the development of a faint smell of what appeared to be dimethyl sulfide suggests that DMSO is being reduced in the reaction, and is thus the oxidant. However, as no aromatization took place when the reaction was conducted under a nitrogen atmosphere, oxygen is clearly involved in the reaction. These observations are consistent with those described for the DMSO oxidation of benzyl alcohols to benzaldehydes, which also produced dimethyl sulfide, yet only proceeded when a stream of air, or t-butyl peroxide, was included in the reaction. ${ }^{36}$

\section{Conclusions}

A simple and efficient oxidative aromatization of 1,3,5-triarylpyrazolines has been described that involves simple heating of the pyrazoline in DMSO in open air. Although the method requires heating up to $48 \mathrm{hr}$, it is a "greener" method as it avoids the use of heavy metal reagents and catalysts, strong oxidants, acidic reagents, and toxic solvents. This method thus compares favorably to some of the other aromatization methods that are currently employed, such as reaction with DDQ in refluxing benzene for $16 \mathrm{hrs} .{ }^{17}$ This method also does not require the use of pure oxygen, which may not be readily available to all chemists, nor does it require microwave heating. Finally, this method may be particularly useful when stronger oxidants must be avoided due to the presence of other oxidizable groups within the pyrazoline substrate.

\section{Experimental Section}

General. Melting points were recorded using a Mel-Temp capillary melting point apparatus and are uncorrected. IR spectra were obtained using a Perkin Elmer Spectrum 100 instrument using attenuated total reflection (ATR). NMR were recorded on a Bruker 300 Avance instrument with signals referenced to residual DMSO- $\mathrm{d}_{6}$ solvent $\left(2.49 \mathrm{ppm}\right.$ for ${ }^{1} \mathrm{H}-\mathrm{NMR}, 39.5 \mathrm{ppm}$ for ${ }^{13} \mathrm{C}$ NMR). Gas chromatograpy and mass spectrometry were performed on a Shimadzu GCMSQP5000. Elemental analyses were performed by Atlantic Microlab in Norcross, GA. TLC were performed on silica gel plates with hexanes:ethyl acetate $(20: 1)$ as eluent. Silica gel (230-400 mesh) was used for column chromatography. DMSO (ACS grade) was obtained from Fisher Scientific and used as received. Starting pyrazolines were prepared according to a general procedure. $^{10}$

General procedure for aromatization of 1,3,5-triarylpyrazolines (Entries 1-10, Table 1). The 1,3,5-triarylpyrazoline $(6 \mathrm{mmol})$ was dissolved in DMSO $(10 \mathrm{~mL})$ in a round-bottomed flask and the solution was heated in an oil bath maintained at $\sim 110{ }^{\circ} \mathrm{C}$ with stirring (the flask was 
fitted with an open $30 \mathrm{~cm}$ condenser which was removed periodically to monitor the reaction by TLC). Once the starting material was consumed (time given in Table 1), the darkened solution was transferred to an Erlenmeyer flask with the addition of $20-30 \mathrm{~mL}$ of water to produce a green to orange solid. The solid was separated from the liquid by filtering or decanting and was dissolved in EtOAc. The solution was washed with water several times, dried over $\mathrm{Na}_{2} \mathrm{SO}_{4}$ and concentrated onto silica gel. The product was chromatographed using hexanes or hexanes:EtOAc (20:1) as eluent to yield the pure pyrazole as a solid (yields given in Table 1). Recrystallization from hexanes or EtOH gave analytical samples with mp and appearance listed in Table 1.

1,3-Diphenyl-5-[(4-trifluoromethyl)phenyl]pyrazole (Entry 5, Table 1). Recrystallized from hexanes. ${ }^{1} \mathrm{H}$ NMR (DMSO-d $\left.d_{6}\right): 7.31(\mathrm{~s}, 1 \mathrm{H}), 7.37-7.52(\mathrm{~m}, 10 \mathrm{H}), 7.75(\mathrm{~d}, J 8.6 \mathrm{~Hz}, 2 \mathrm{H}), 7.92(\mathrm{~d}$, $J 7.4 \mathrm{~Hz}, 2 \mathrm{H}$ ). ${ }^{13} \mathrm{C}$ NMR (DMSO-d $)$ ): 106.2, 124.0 (q, $\left.J 272 \mathrm{~Hz}\right), 125.4(2 \mathrm{C}), 125.5$ (q, $J 3.6$ $\mathrm{Hz}), 128.1,128.2,128.4,128.6$ (q, $J 32 \mathrm{~Hz}$, partially overlapping at 128.8), 128.8, 129.2, 129.3, 132.4, 133.9 (q, $J 1.4 \mathrm{~Hz}) . \quad$ IR $\left(\mathrm{cm}^{-1}\right): 3064,2962,1596,1494,1323,1163,1119,1110,1068$, 1017, 838, 758, 747, 690. MS (EI): $m / z$ 364. Analysis calcd for $\mathrm{C}_{22} \mathrm{H}_{15} \mathrm{~F}_{3} \mathrm{~N}_{2}$ (364.36): C, 72.52; H, 4.15; N, 7.69. Found: C, 72.59; H, 4.27; N, 7.58.

3-(4-Cyanophenyl)-1,5-diphenylpyrazole (Entry 7, Table 1). Recrystallized from hexanes. ${ }^{1} \mathrm{H}$ NMR (DMSO- $\left.d_{6}\right): 7.28-7.43(\mathrm{~m}, 11 \mathrm{H}), 7.91(\mathrm{~d}, J 8.4 \mathrm{~Hz}, 2 \mathrm{H}), 8.10(\mathrm{~d}, J 8.4 \mathrm{~Hz}, 2 \mathrm{H}) .{ }^{13} \mathrm{C}$ NMR (DMSO- $d_{6}$ ): 106.2, 110.3, 118.9, 125.4, 126.0, 128.1, 128.5, 128.7, 128.7, 129.2, 129.6, 132.9, 137.1, 139.5, 144.6, 149.3. IR $\left(\mathrm{cm}^{-1}\right): 3061,2224,1610,1595,1500,1484,1454,1359,1178$, 971, 846, 796, 760, 694. MS (EI): $m / z$ 321. Analysis calcd for $\mathrm{C}_{22} \mathrm{H}_{15} \mathrm{~N}_{3}$ (321.37): C, 82.22; $\mathrm{H}$, 4.70; N, 13.08. Found: C, 82.15; H, 4.77; N, 13.03 .

5-(4-Bromophenyl)-3-(4-methylphenyl)-1-phenylpyrazole (Entry 9, Table 1). Recrystallized from hexanes. ${ }^{1} \mathrm{H}$ NMR (DMSO- $\left.d_{6}\right): 2.33(\mathrm{~s}, 3 \mathrm{H}), 7.15(\mathrm{~s}, 1 \mathrm{H}), 7.20-7.44(\mathrm{~m}, 9 \mathrm{H}), 7.57$ (d, $J$ $8.4 \mathrm{~Hz}, 2 \mathrm{H}), 7.79(\mathrm{~d}, J 8.1 \mathrm{~Hz}, 2 \mathrm{H}) .{ }^{13} \mathrm{C}$ NMR (DMSO- $\left.d_{6}\right): 20.9,105.4,121.9,125.3,125.3$, $127.9,129.2,129.2,129.3,129.7,130.4,131.6,137.4,139.6,142.8,151.1 . \quad$ IR $\left(\mathrm{cm}^{-1}\right): 3063$, 2952, 2917, 1593, 1497, 1481, 1454, 1011, 971, 827, 785, 771, 693. MS (EI): $m / z ~ 388, ~ 390$. Analysis calcd for $\mathrm{C}_{22} \mathrm{H}_{17} \mathrm{BrN}_{2}$ (389.30): C, 67.88; H, 4.40; N, 7.20. Found: C, 67.83; H, 4.41; N, 7.18 .

3-(4-Chlorophenyl)-5-(4-methylphenyl)-1-phenylpyrazole (Entry 10, Table 1). ${ }^{1} \mathrm{H}$ NMR (DMSO-d $\left.)_{6}\right): 2.29(\mathrm{~s}, 3 \mathrm{H}), 7.14-7.18(\mathrm{~m}, 5 \mathrm{H}), 7.30-7.43(\mathrm{~m}, 5 \mathrm{H}), 7.50(\mathrm{~d}, J 8.5 \mathrm{~Hz}, 2 \mathrm{H}), 7.92$ (d, $J 8.4 \mathrm{~Hz}, 2 \mathrm{H}) .{ }^{13} \mathrm{C}$ NMR (DMSO- $\left.d_{6}\right): 20.8,105.2,125.3,126.9,127.0,127.8,128.3,128.8$, 129.1, 129.2, 131.6, 132.5, 138.1, 139.7, 144.3, 149.8. IR ( $\left.\mathrm{cm}^{-1}\right): 3047,2911,1593,1492,1438$, 1353, 1089, 972, 955, 823, 780, 692. MS (EI): $\mathrm{m} / z$ 344, 346. Analysis calcd for $\mathrm{C}_{22} \mathrm{H}_{17} \mathrm{ClN}_{2}$ (344.84): C, 76.63; H, 4.97; N, 8.12. Found: C, 76.60; H, 4.97; N, 8.10.

\section{Acknowledgements}

We thank our department for partial funding of this research. 


\section{References}

1. Naoum, F.; Kasiotis, K. M.; Magiatas, P.; Haroutounian, S. A. Molecules 2007, 12, 1259. http://dx.doi.org/10.3390/12071259

2. Menozzi, G.; Schenon, P.; Mositi, L. J. Heterocycl. Chem. 1993, 30, 997. http://dx.doi.org/10.1002/jhet.5570300427

3. Singh, S.; Naithani, R.; Aggarwal, R.; Prakesh, O. Ind. J. Heterocycl. Chem. 2001, 11, 27.

4. Liu, X.; Huang, X.; Lin, W.; Wang, D.; Diao, Y.; Li, H.; Hui, X.; Wang, Y.; Xu, A.; Wu, D.; Ke, D. Bioorg. Med. Chem. Lett. 2011, 21, 2949. http://dx.doi.org/10.1016/j.bmcl.2011.03.063

5. Rudnitskaya, A.; Huynh, K.; Torok, B.; Stieglitz, K. J. Med. Chem. 2009, 52, 878. http://dx.doi.org/10.1021/jm800720a

6. Ashton, W.; Hutchins, S.; Greenlee, W.; Doss, G.; Chang, R.; Lotti, V.; Faust, K.; Chen, T.; Zingaro, G.; Kivlighn, S.; Siegl, P. J. Med. Chem. 1993, 36, 3695.

7. Rao, V. K.; Tiwari, R.; Chhikara, B. S.; Shirazi, A. N.; Paranq, K.; Kumar, A. RSC Adv. 2013, 3, 15396. http://dx.doi.org/10.1039/c3ra41830h

8. Singer, R. A.; Dore, M.; Sieser, J. E.; Berliner, M. A. Tetrahedron Lett. 2006, 47, 3727. http://dx.doi.org/10.1016/j.tetlet.2006.03.132

9. Qian, Y.; Karpus, J.; Kabil, O.; Zhang, S.; Zhu, H.; Banerjee, R.; Zhao, J.; He, C. Nature Comm. 2011, 2, 495.

http://dx.doi.org/10.1038/ncomms 1506

10. Levai, A. Arkivoc 2005, (ix), 344.

11. Gladstone, W. A. F.; Norman, R. O. C. J. Chem. Soc., Chem. Commun. 1966, 1536.

12. Auwers, K.; Heimke, P. Liebigs Ann. Chem. 1927, 458, 186. http://dx.doi.org/10.1002/jlac.19274580112

13. Smith, L. I.; Howard, K. L. J. Am. Chem. Soc. 1943, 65, 159. http://dx.doi.org/10.1021/ja01242a008

14. Sabitha, G.; Reddy, G. S. K.; Reddy, C. S.; Fatima, N.; Yadav, J. S. Synthesis 2003, 1267.

15. Azarifar, D.; Maleki, B. Synth. Commun. 2005, 35, 2581. http://dx.doi.org/10.1080/00397910500214136

16. Azarifar, D.; Maleki, B.; Sahraei, M. J. Heterocycl. Chem. 2008, 45, 563. http://dx.doi.org/10.1002/jhet.5570450241

17. Beniyama, Y.; Matsuno, K.; Miyachi, H. Bioorg. Med. Chem. Lett. 2013, 23, 1662. http://dx.doi.org/10.1016/j.bmcl.2013.01.054

18. Gamapwar, S. V.; Tale, N. P.; Karade, N. N. Synth. Commun. 2012, 42, 2617. http://dx.doi.org/10.1080/00397911.2011.563449

19. Azarifar, D.; Gharshasbi, A. Heterocycles 2006, 68, 1209. http://dx.doi.org/10.3987/COM-06-10701

20. Azarifar, D.; Maleki, B. Heterocycles 2005, 65, 865. 


\section{http://dx.doi.org/10.3987/COM-04-10276}

21. Chai, L.; Zhao, Y.; Sheng, Q.; Liu, Z. -Q. Tetrahedron Lett. 2006, 47, 9283. http://dx.doi.org/10.1016/j.tetlet.2006.10.108

22. Zolfigol, M. A.; Azarifar, D.; Maleki, B. Tetrahedron Lett. 2004, 45, 2181. http://dx.doi.org/10.1016/j.tetlet.2004.01.038

23. Zolfigol, M. A.; Azarifar, D.; Mallakpour, S.; Mohammadpoor-Baltork, I.; Forghaniha, A.; Maleki, B.; Abdollahi-Alibeik, M. Tetrahedron Lett. 2006, 47, 833. http://dx.doi.org/10.1016/j.tetlet.2005.11.088

24. Maleki, B.; Veisi, H. Bull. Korean Chem. Soc. 2011, 32, 4366. http://dx.doi.org/10.5012/bkcs.2011.32.12.4366

25. Azarifar, D.; Khosravi, K.; Veisi, R. -A. Arkivoc 2010, (ix), 178.

26. Kumar, A.; Maurya, R. A.; Sharma, S. Bioorg. Med. Chem. Lett. 2009, 19, 4432. http://dx.doi.org/10.1016/j.bmcl.2009.05.056

27. Liu, Y.; Mao, D.; Lou, S.; Qian, J.; Xu, Z. -Y. Org. Prep. Proced. Int. 2009, 41, 237. http://dx.doi.org/10.1080/00304940902956119

28. Han, B.; Liu, Z.; Liu, Q.; Yang, L.; Liu, Z.; Yu, W. Tetrahedron 2006, 62, 2492. http://dx.doi.org/10.1016/j.tet.2005.12.056

29. Nakamichi, N.; Kawashita, Y.; Hayashi, M. Synthesis 2004, 1015.

30. Nakamichi, N.; Kawashita, Y.; Hayashi, M. Org. Lett. 2002, 4, 3955. http://dx.doi.org/10.1021/o10268135

31. Sajiki, H.; Kume, A.; Hattori, K.; Hirota, K. Tetrahedron Lett. 2002, 43, 7247. http://dx.doi.org/10.1016/S0040-4039(02)01622-2

32. Ananthnag, G. S.; Adhikari, A.; Balakrishna, M. S. Catal. Commun. 2014, 43, 240. http://dx.doi.org/10.1016/j.catcom.2013.09.002

33. Kadu, M. V. Orient. J. Chem. 2010, 26, 1109.

34. Lokhande, P. D.; Dalvi, B. A.; Humne, V. T.; Nawghare, B. R.; Kareem, A. Ind. J. Chem. 2014, 53B, 1091.

35. Huang, Y.; Katzenellenbogen, J. Org. Lett. 2000, 2, 2833. http://dx.doi.org/10.1021/o10062650

36. Traynelis, V. J.; Hergenrother, W. L. J. Am. Chem. Soc. 1964, 86, 298. http://dx.doi.org/10.1021/ja01056a050

37. El-Rayyes; Al-Hajjar. J. Heterocycl. Chem. 1977, 14, 367.

38. Gruenanger; Langella. Gazz. Chim. Ital. 1960, 90, 229.

39. Foote, R. S.; Beam, C. F.; Hauser, C. R. J. Heterocycl. Chem. 1970, 7, 589. http://dx.doi.org/10.1002/jhet.5570070318

40. Deng, X.; Mani, N. S. J. Org. Chem. 2008, 73, 2412. http://dx.doi.org/10.1021/jo7026195 